\title{
Mortalidade por violência contra mulheres antes e durante a pandemia de Covid-19. Ceará, 2014 a 2020
}

\author{
Mortality from violence against women before and during the \\ Covid-19 pandemic. Ceará, 2014 to 2020
}

Elisângela Rodrigues Chagas ${ }^{\mathbf{1}}$, Fernando Virgílio Albuquerque de Oliveira ${ }^{2}$, Raimunda Hermelinda Maia Macena²

DOI: $10.1590 / 0103-1104202213204$

RESUMO Compreendendo a importância do monitoramento da violência contra mulheres, este estudo teve como objetivo analisar o comportamento da curva de crimes violentos, letais e intencionais contra mulheres, no estado do Ceará, nos últimos anos e discutir acerca dos aspectos que envolvem a curva epidemiológica dos crimes letais contra a mulher, principalmente com o início da pandemia de Covid-19. Trata-se de uma pesquisa ecológica, utilizando os dados secundários disponíveis na plataforma da Secretaria de Segurança Pública e Defesa Social do estado do Ceará entre os anos de 2014 a 2020 . A coleta foi realizada no mês de janeiro de 2021, os dados foram analisados com auxílio do programa Excel. Constatou-se que a violência contra a mulher no estado do Ceará encontra-se em ascensão e que anos com eventos sanitários atípicos, como a pandemia da Covid-19, tendem a impactar negativamente a vida em sociedade e mais diretamente a vida das mulheres. Torna-se essencial que as autoridades, as instituições, organizações sociais, comunidade acadêmica, profissionais de todos os setores e serviços públicos e privados estejam sensibilizados e empenhados em cobrar a efetivação das políticas de enfrentamento alinhadas a rede de serviços, principalmente no momento de maior vulnerabilidade da pandemia.

PALAVRAS-CHAVES Violência contra a mulher. Isolamento social. Covid-19.

ABSTRACT Understanding the importance of monitoring in confront violence against women, this study aimed to analyze the behavior of the curve of violent, lethal and intentional crimes against women in the state of Ceará in recent years and discuss aspects that involve the epidemiological curve of lethal crimes against women, especially with the beginning of the Covid-19 pandemic. This is an ecological survey, using the secondary data available on the platform of the Secretariat of Public Security and Social Defense of the state of Ceará between the years 2014 to 2020. The collection was carried out in January 2021, the data were purchased with the aid of the Excel program. It was found that violence against women in the state of Ceará is on the rise and that years with atypical health events, such as the Covid-19 pandemic, tend to have a negative impact on life in society and more directly on women lives. It is essential that authorities, institutions, social associations, the academic community, professionals from all sectors in public and private services

1 Escola de Saúde Pública do Ceará (ESP/CE) -

Fortaleza (CE), Brasil.

elisangelachagas.psi@gmail. com

2 Universidade Federal do Ceará (UFC) - Fortaleza (CE), Brasil. are sensitized and committed to demanding the implementation of confrontation policies aligned with the service network, especially at the moment of greatest vulnerability of the pandemic.

KEYWORDS Violence against women. Social isolation. Covid-19. 


\section{Introdução}

A violência é definida como a utilização da força física, de poder ou em forma de ameaça contra si, outra pessoa ou contra um grupo e/ ou comunidade, que resulte em lesão, dano psicológico, privação, deficiência de desenvolvimento ou morte. Trata-se de um fenômeno social, fazendo-se presente em múltiplos lugares e classes sociais, representando um grande problema de saúde pública, visto que impacta de forma significativa a vida em sociedade'.

Atos violentos são responsáveis pela morte de milhares de pessoas anualmente, principalmente daquelas com idade entre 15 e 44 anos. Dentre esse público, destaca-se a violência direcionada às mulheres, que é definida como toda e qualquer ação violenta realizada com base no gênero ${ }^{2}$.

O 'Relatório Mundial sobre a Prevenção da Violência' publicado pela OMS, no ano de 2014, afirma que a cada três mulheres, uma foi vítima de violência física e/ou sexual em algum momento da vida, o que reflete a magnitude da violência contra a mulher na realidade atual. Destaca-se também o fato de que tais atos violentos praticados contra as mulheres normalmente partem de parceiros íntimos, o que torna a situação ainda mais ampla e complexa ${ }^{3}$.

Ainda nesse sentido, o 'Mapa da Violência 2015: homicídio de mulheres no Brasil', elaborado pela Faculdade Latino-Americana de Ciência Sociais, revelou que o Brasil é o quinto país, dentro de um total de 83 , que mais comete violência contra mulheres, apresentando 48 vezes mais homicídios que o Reino Unido, por exemplo. A taxa total é de 4,8 homicídios por 100 mil mulheres, um índice muito superior ao encontrado em outras partes do mundo 4 .

No que diz respeito às políticas públicas direcionadas ao enfrentamento e combate à violência contra a mulher, destaca-se que estas vêm sendo desenvolvidas desde a década de 1980, buscando minimizar a incidência e evitar a ocorrência do agravo em questão, promovendo estratégias de atendimento e proteção às mulheres vítimas de violência. $\mathrm{O}$ Programa de Assistência Integrada à Saúde da Mulher (Paism), de 1983, é considerado o primeiro programa criado com o conceito de Atenção Integral à Saúde da Mulher. Embora não seja uma política voltada especificamente ao enfrentamento à violência, abarca o fenômeno devido a compreensão de saúde ampliada ${ }^{5}$. Em termos de segurança pública, a partir do Decreto $n^{\circ}$ 23.769/1985, no estado de São Paulo, foi criada a primeira Delegacia Especializada de Atendimento à Mulher (Deam) ${ }^{6}$.

Entretanto, o que se percebe é que, ainda assim, as intervenções realizadas com as mulheres que procuram os serviços de saúde e sugerem situação de violência se limitam a cuidados das sequelas e/ou sinais físicos. Pesquisas revelam o sentimento de impotência sinalizado por profissionais da saúde diante da complexidade do fenômeno da violência, percepções estereotipadas que naturalizam comportamentos agressivos e violentos em homens e passividade em mulheres, além da dificuldade em conceber a violência contra mulher como uma questão de saúde pública ${ }^{5}$.

Nesse contexto das propostas de inclusão da perspectiva de gênero nas políticas públicas para a reconstrução de uma sociedade mais justa para todas e todos, pode-se apontar a importância da criação de estatísticas confiáveis com intuito de revelar a realidade desse fenômeno ${ }^{8}$.

Do ponto de vista da segurança pública, no estado do Ceará, a Secretaria de Segurança Pública e Defesa Social (SSPDS), vinculada à Superintendência de Pesquisa e Estratégias de Segurança Pública do Estado do Ceará (Supesp), acompanha a evolução da criminalidade e da violência. Mensalmente são publicados na plataforma os dados estatísticos oriundos de diversas fontes, sendo a principal o Sistema de Informações Policiais?.

Compreendendo a importância da notificação e do controle epidemiológico no combate à violência e proteção à integridade física e 
moral das mulheres vítimas de violência, torna-se necessário o seguinte questionamento: qual o comportamento dos dados de mortalidade de crimes violentos, letais e intencionais contra mulheres nos últimos anos e durante o ano de 2020, em que iniciou-se a pandemia de Covid-19?

Deste modo, este estudo analisa o comportamento da curva de crimes violentos, letais e intencionais contra mulheres no Ceará, entre os anos 2014 e 2020, pretendendo identificar o perfil recente de notificações de casos de violência contra a mulher no estado e discutir acerca dos aspectos que envolvem a curva epidemiológica dos crimes letais contra a mulher.

\section{Metodologia}

Trata-se de uma pesquisa ecológica, que utiliza dados secundários disponíveis na plataforma da SSPDS. O estado do Ceará é uma unidade federativa localizada na região Nordeste do Brasil, com população estimada de 9.187 .103 pessoas, distribuídas em 184 municípios, em um território de $148.894,441 \mathrm{~km}^{2} 10$.

Seu território é dividido administrativamente pela SSPDS em 19 Áreas Integradas de Segurança (AIS), sendo as dez primeiras compondo o município de Fortaleza (AIS1 a AIS10) e as demais agrupando os outros municípios do estado (AIS11 a AIS19) ${ }^{9}$. A amostragem foi por conveniência e foram incluídos na amostra todos os dados considerados relevantes para os objetivos deste estudo, totalizando uma base com 2.079 casos ocorridos no período de 2014 a 2020.

Foram coletados os dados disponíveis no site: https://www.sspds.ce.gov.br/, na aba Estatísticas. Estabeleceu-se como critérios de inclusão no estudo: homicídios de mulheres de todas as idades, caracterizados como feminicídio ou não, no território do estado do Ceará, disponíveis na base de dados pública do site da SSPDS de todos os anos disponibilizados. Foram excluídos os dados referentes ao ano de 2013, por estar disponível na plataforma somente o número total de vítimas, sem especificação das variáveis necessárias para o estudo, além de homicídios de mulheres com dados incompletos ou inconsistentes, que inviabilizariam a análise do perfil epidemiológico.

A coleta de dados foi realizada no mês de janeiro de 2021, especificando-se as informações inerentes à questão norteadora, conforme definida a população e amostra. Foram utilizados os dados que possuíam semelhança ao objeto estudado e que permitiram discussão e análise da temática do estudo. A escolha pelo período de estudo para análise de série histórica se deu pelo fato de que a plataforma da SSPDS disponibiliza os dados de janeiro de 2014 até o momento em que esta pesquisa foi realizada.

A base escolhida realiza um compilado mensal dos dados sobre crimes violentos letais e intencionais que engloba os boletins de ocorrência, termos circunstanciados de ocorrência e inquéritos policiais, além de fontes secundarias, relatórios que são enviados através do Comando de Policiamento do Interior Sul e Norte (CPI), Coordenadoria Integrada de Operações de Segurança (Ciops) e Perícia Forense do Estado do Ceará (Pefoce). A agilidade da consolidação mensal das informações no site da SSPDS tornou-se, portanto, um fator para justificar a fonte para este estudo. Além disso, os dados são compilados e disponibilizados de forma livre pela plataforma a cada mês, sem a possibilidade de reajustes (inserção ou exclusão de casos), que inviabilizariam considerar a base como inalterável e elegível para o estudo.

As variáveis incluídas para análise epidemiológica foram: sexo (apenas o feminino), idade da vítima, natureza do fato, município da ocorrência, meio de agressão utilizado, dia, mês e ano de ocorrência. Entende-se por crimes violentos letais e intencionais os homicídios dolosos, ou seja, cometidos intencionalmente, feminicídio, lesão corporal seguida de morte e roubo seguido de morte, independente da arma ou meio utilizado, que teve como resultado a morte das vítimas ${ }^{\mathbf{1 0}}$. Foram utilizados, ainda, 
dados de estimativa de população residente no Ceará fornecidos pelo Instituto Brasileiro de Geografia e Estatística (IBGE) para os cálculos de taxa de mortalidade.

A tipificação do crime como feminicídio só passou a ser utilizada na fonte de dados a partir de 2017 (com poucos casos naquele ano), não havendo essa natureza nos anos anteriores da amostra. Dessa forma, deve-se observar essa variável com cautela e considerar que seja possível que alguns crimes contabilizados como homicídios dolosos contra mulheres, de 2014 a 2017, possam ter sido feminicídios.

Após a coleta de dados, estes foram agrupados em planilhas do programa Excel for Windows $^{\circledR}$, consolidados e padronizados. O referido programa foi utilizado, ainda, para os cálculos de análise descritiva e construções de gráficos e tabelas do estudo. Realizou-se, ainda, a análise da tendência temporal por meio de gráficos de linhas e modelos de regressão joinpoint (regressão linear segmentada por pontos de inflexão de Poisson) a partir dos dados de taxa de mortalidade ao longo do período do estudo através do software. Por meio da definição dos segmentos, efetuou-se a estimativa e testou-se a Variação Percentual Anual (APC) e a Variação Percentual Anual Média (AAPC), com seus respectivos IC95\%, permitindo-se a demonstração de crescimento (APC positivos), redução (APC negativos) ou manutenção $(\mathrm{APC}=0)$ da tendência dos dados analisados.

Todos os aspectos ético-legais que envolvem pesquisas com seres humanos e/ou informações acerca destes foram respeitados durante a realização desta pesquisa, de acordo com a Resolução no ${ }^{\circ} 466 / 2012$. Por tratar-se de um estudo com dados secundários disponíveis e de acesso público no site do órgão responsável, não foi necessária submissão ao comitê de ética, podendo-se iniciar as coletas sem a imposição desta etapa. Ainda assim, os pesquisadores mantiveram os princípios éticos para não maleficência das pessoas incluídas na amostra, respeitando os dados de identificação dos casos apenas em análises internas e mantendo o anonimato na apresentação dos resultados.

\section{Resultados}

No presente estudo, observou-se que a média total da mortalidade no Ceará foi de $6,4( \pm 1,9)$ óbitos para cada 100 mil mulheres entre os anos de 2014 a 2020 . Os anos que estiveram acima da referida média foram 2017, 2019 e 2020, com 7,7, 10 e 7,1 óbitos a cada 100 mil mulheres, respectivamente. Além disso, houve incremento de $43,5 \%$ de 2019 para 2020 (gráfico 1).

Podemos constatar ainda que a taxa de mortes se mantém ou cresce com o passar do tempo. Os dois incrementos que se destacam, além do supracitado de 2019 para 2020, são de 2016 para 2017 , com $67,7 \%$, e de 2017 para 2018, com $30 \%$. 
Gráfico 1. Taxa de mortalidade por crimes violentos letais e intencionais contra mulheres segundo ano de ocorrência. Ceará, 2014 a 2020

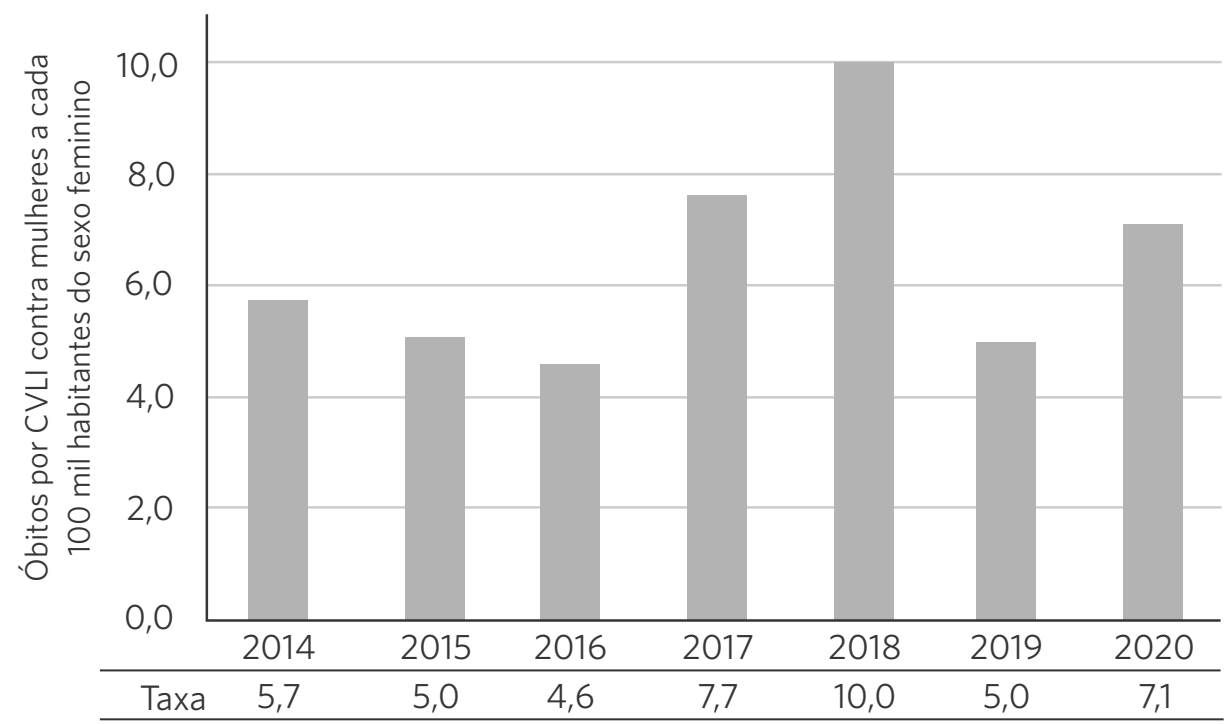

Fonte: elaboração própria.

Em relação à análise temporal, não foram observados momentos distintos de variação das taxas de feminicídio. Entretanto, pode ser observada variação das taxas de mortalidade no período de 2014 a 2020 , de $5,82 \%$ ao ano (-8.9 - 22.9), embora sem significância estatística. Não foi conclusiva a APC, tendo em vista a limitação da série histórica, entretanto os achados revelam uma potencial tendência ao crescimento das taxas de feminicídio.

Quanto à natureza do crime, os três primeiros registros de feminicídio só foram apontados em dezembro do ano de 2017, ou seja, trinta e três meses seguintes à sanção da Lei $\mathrm{n}^{\mathrm{o}} 13.104$, totalizando menos de $1 \%$ das mortes naquele ano. Nos anos seguintes, o registro de feminicídio continua com porcentagem baixa em relação aos homicídios dolosos.
Outra observação que a tabela 1 apontada é uma redução dos números de feminicídio para $8,1 \%$ no ano de 2020 , contra $14,7 \%$ no ano anterior. De forma invertida, em 2019 tivemos $82,8 \%$ em homicídios dolosos contra $89,9 \%$ em 2020 (tabela 1).

Sobre o meio da agressão, observa-se que, em todos os anos mencionados, a arma de fogo é o que mais se destaca, seguido das armas brancas. A menor proporção de mulheres mortas por arma de fogo foi em 2016, com $62,2 \%$ do total dos assassinatos. Em 2018, ocorreu a maior taxa de mortes por arma de fogo (80,3\%), enquanto que $78,5 \%$ do total de mulheres mortas foi por arma de fogo no ano em que teve início o isolamento social pela Covid-19. 
Tabela 1. Número e porcentagem de crimes violentos letais e intencionais contra mulheres segundo característica da agressão, faixa etária, mês e ano de ocorrência. Ceará, 2014 a 2020

\begin{tabular}{|c|c|c|c|c|c|c|c|c|c|c|c|c|c|c|c|}
\hline \multirow{2}{*}{$\begin{array}{l}\text { Característica } \\
\text { da agressão }\end{array}$} & \multicolumn{2}{|l|}{2014} & \multicolumn{2}{|l|}{2015} & \multicolumn{2}{|l|}{2016} & \multicolumn{2}{|l|}{2017} & \multicolumn{2}{|l|}{2018} & \multicolumn{2}{|l|}{2019} & \multicolumn{2}{|l|}{2020} & \multirow{2}{*}{$\begin{array}{l}\text { Total } \\
\text { da } \\
\text { série }\end{array}$} \\
\hline & $\mathbf{N}$ & $\%$ & $\mathbf{N}$ & $\%$ & $\mathbf{N}$ & $\%$ & $\mathbf{N}$ & $\%$ & $\mathbf{N}$ & $\%$ & $\mathbf{N}$ & $\%$ & $\mathbf{N}$ & $\%$ & \\
\hline \multicolumn{16}{|c|}{ Natureza do crime } \\
\hline Feminicídio & & 0,0 & & 0,0 & & 0,0 & 3 & 0,8 & 27 & 5,8 & 34 & 14,7 & 27 & 8,1 & 91 \\
\hline $\begin{array}{l}\text { Homicídio } \\
\text { doloso }\end{array}$ & 257 & 99,2 & 223 & 97,4 & 201 & 96,2 & 337 & 95,5 & 420 & 90,9 & 192 & 82,8 & 301 & 89,9 & 1.931 \\
\hline $\begin{array}{l}\text { Lesão corporal } \\
\text { seguida de } \\
\text { morte }\end{array}$ & & 0,0 & 2 & 0,9 & 2 & 1,0 & 2 & 0,6 & 1 & 0,2 & 1 & 0,4 & 1 & 0,3 & \\
\hline $\begin{array}{l}\text { Roubo seguido } \\
\text { de morte }\end{array}$ & 2 & 0,8 & 4 & 1,7 & 6 & 2,9 & 11 & 3,1 & 14 & 3,0 & 5 & 2,2 & 6 & 1,8 & 48 \\
\hline \multicolumn{16}{|c|}{ Meio de agressão } \\
\hline Arma branca & 43 & 16,6 & 38 & 16,6 & 54 & 25,8 & 49 & 13,9 & 48 & 10,4 & 43 & 18,5 & 44 & 13,1 & 319 \\
\hline Arma de fogo & 183 & 70,7 & 161 & 70,3 & 130 & 62,2 & 270 & 76,5 & 371 & 80,3 & 156 & 67,2 & 263 & 78,5 & 1.534 \\
\hline Outras & 31 & 12,0 & 23 & 10,0 & 23 & 11,0 & 33 & 9,3 & 40 & 8,7 & 33 & 14,2 & 28 & 8,4 & 211 \\
\hline Não & 2 & 0,8 & 7 & 3,1 & 2 & 1,0 & 1 & 0,3 & 3 & 0,6 & & 0,0 & & 0,0 & 15 \\
\hline \multicolumn{16}{|c|}{ Mês de ocorrência } \\
\hline Janeiro & 33 & 12,7 & 18 & 7,9 & 21 & 10,0 & 10 & 2,8 & 52 & 11,3 & 15 & 6,5 & 30 & 9,0 & 179 \\
\hline Fevereiro & 15 & 5,8 & 23 & 10,0 & 20 & 9,6 & 13 & 3,7 & 44 & 9,5 & 16 & 6,9 & 30 & 9,0 & 161 \\
\hline Março & 35 & 13,5 & 22 & 9,6 & 20 & 9,6 & 18 & 5,1 & 41 & 8,9 & 13 & 5,6 & 30 & 9,0 & 179 \\
\hline Abril & 18 & 6,9 & 28 & 12,2 & 20 & 9,6 & 29 & 8,2 & 32 & 6,9 & 25 & 10,8 & 31 & 9,3 & 183 \\
\hline Maio & 24 & 9,3 & 27 & 11,8 & 14 & 6,7 & 18 & 5,1 & 32 & 6,9 & 17 & 7,3 & 40 & 11,9 & 172 \\
\hline Junho & 24 & 9,3 & 18 & 7,9 & 16 & 7,7 & 25 & 7,1 & 33 & 7,1 & 17 & 7,3 & 32 & 9,6 & 165 \\
\hline Julho & 20 & 7,7 & 10 & 4,4 & 8 & 3,8 & 33 & 9,3 & 41 & 8,9 & 27 & 11,6 & 23 & 6,9 & 162 \\
\hline Agosto & 15 & 5,8 & 12 & 5,2 & 12 & 5,7 & 35 & 9,9 & 34 & 7,4 & 13 & 5,6 & 15 & 4,5 & 136 \\
\hline Setembro & 12 & 4,6 & 17 & 7,4 & 14 & 6,7 & 41 & 11,6 & 41 & 8,9 & 21 & 9,1 & 25 & 7,5 & 171 \\
\hline Outubro & 30 & 11,6 & 18 & 7,9 & 19 & 9,1 & 39 & 11,0 & 33 & 7,1 & 20 & 8,6 & 32 & 9,6 & 19 \\
\hline Novembro & 18 & 6,9 & 13 & 5,7 & 21 & 10,0 & 46 & 13,0 & 39 & 8,4 & 24 & 10,3 & 24 & 7,2 & 185 \\
\hline Dezembro & 15 & 5,8 & 23 & 10,0 & 24 & 11,5 & 46 & 13,0 & 40 & 8,7 & 24 & 10,3 & 23 & 6,9 & 195 \\
\hline \multicolumn{16}{|c|}{ Faixa etária } \\
\hline 0 a 9 anos & 1 & 0,4 & 3 & 1,3 & 4 & 1,9 & 4 & 1,1 & 4 & 0,9 & 5 & 2,2 & 7 & 2,1 & 28 \\
\hline 10 a 19 anos & 56 & 21,6 & 32 & 14,0 & 27 & 12,9 & 77 & 21,8 & 114 & 24,7 & 43 & 18,5 & 72 & 21,5 & 42 \\
\hline 20 a 29 anos & 76 & 29,3 & 62 & 27,1 & 74 & 35,4 & 112 & 31,7 & 133 & 28,8 & 68 & 29,3 & 100 & 29,9 & 625 \\
\hline 30 a 39 anos & 50 & 19,3 & 51 & 22,3 & 48 & 23,0 & 53 & 15,0 & 100 & 21,6 & 52 & 22,4 & 81 & 24,2 & 435 \\
\hline 40 a 49 anos & 28 & 10,8 & 40 & 17,5 & 28 & 13,4 & 37 & 10,5 & 48 & 10,4 & 28 & 12,1 & 36 & 10,7 & 245 \\
\hline 50 a 59 anos & 15 & 5,8 & 13 & 5,7 & 14 & 6,7 & 17 & 4,8 & 23 & 5,0 & 11 & 4,7 & 13 & 3,9 & 106 \\
\hline 60 a 69 anos & 2 & 0,8 & 6 & 2,6 & 5 & 2,4 & 5 & 1,4 & 4 & 0,9 & 6 & 2,6 & 9 & 2,7 & 37 \\
\hline 70 anos e mais & 7 & 2,7 & 6 & 2,6 & 2 & 1,0 & 3 & 0,8 & 10 & 2,2 & 5 & 2,2 & 10 & 3,0 & 43 \\
\hline Total por ano & 259 & & 229 & & 209 & & 353 & & 462 & & 232 & & 335 & & 2.079 \\
\hline
\end{tabular}

Fonte: elaboração própria. 
Em relação às médias das taxas de mortalidade por mês de 2014 a 2020, observou-se a seguinte distribuição (em número de casos a cada 100 mil mulheres residentes): janeiro com média equivalente a $0,6( \pm 0,3)$; fevereiro com $0,5( \pm 0,2)$; março com $0,6( \pm 0,2)$; abril com $0,6( \pm 0,1)$; maio com $0,5( \pm 0,2)$; junho com $0,5( \pm 0,1)$; julho com $0,5( \pm 0,3)$; agosto com $0,4( \pm 0,2)$; setembro com $0,5( \pm 0,3)$; outubro com $0,6( \pm 0,2)$; novembro com $0,6( \pm 0,3)$ e dezembro com $0,6( \pm 0,2)$.

No que se refere à taxa de mortalidade dos meses de 2020 em comparação com a média para a série histórica, três meses destacaram-se com valores acima da referida média: abril, maio e junho. Abril de 2020 apresentou taxa de 0,6 óbitos a cada 100 mil mulheres, equivalente a $14,1 \%$ a mais quando comparado com a média do mesmo mês em anos anteriores. Já o mês de maio apresentou um aumento de 37,5\% e junho $25 \%$ em relação à média da série histórica ao apresentarem, respectivamente, 0,9 e 0,7 óbitos a cada 100 mil mulheres. Os três meses representam a fase de isolamento mais rígida durante a pandemia por Covid-19 no Ceará, de acordo com os Decretos n ${ }^{\circ} 33.536, n^{\circ} 33.608$ e n $^{\circ} 33.631$.

No quesito faixa etária, conforme pode-se observar na tabela 1, os números que se destacam são os homicídios dos 10 aos 49 anos, sendo pico as vítimas com idade entre 20 e 39 anos. As mulheres jovens foram as maiores vítimas de homicídio no Ceará durante os anos de 2014 a 2020. Um dado que chama a atenção é o número de vítimas com faixa etária de 10 a 19 anos. Como podemos observar, nos anos de 2014, 2017, 2018 e 2020 , no total de mulheres assassinadas, mais de 20\% eram meninas com idades de 10 a 19 anos. Em 2018, entre a faixa etária de 10 a 19 anos, essa porcentagem é ainda maior, onde observamos 25,6\% de meninas mortas. Em números absolutos, foram mortas no Ceará 118 meninas, de um total 462 vítimas naquele ano.

As variações observadas relacionadas às idades das mulheres da amostra, destacam para uma idade mínima de 0 anos e máxima de 91 , com mediana de 28 anos, percentil $25 \%$ de 20 anos e percentil $75 \%$ de 38 anos.

\section{Discussão}

No Brasil, no ano de 2018, o número total de mulheres assassinadas chegou a 4.519. Esse número corresponde a uma taxa de 4,3 mortes para cada 100 mil mulheres. Dos 27 estados do País, 19 obtiveram redução nas taxas de assassinatos de mulheres entre os anos 2017 e 2018. O estado do Ceará está entre os três que apresentaram taxa maior que $20 \%$ em crimes letais contra mulheres. Entre os anos 2008 a 2018, o Brasil aponta para um aumento de $4,2 \%$ no assassinato de mulheres, e o Ceará apresenta um crescimento de $278,6 \%$ neste tipo de crime letal"1.

Conforme descrito nos resultados, o presente estudo observou um aumento no total geral de homicídios dolosos e feminicídios no ano de 2020 em relação ao ano de 2019. A pandemia pelo novo coronavírus teve início, no Ceará, no ano de 2020, devendo-se levar em consideração que este representa um período de maior vulnerabilidade para mulheres devido às suas consequências, como o isolamento social e a maior manutenção de vítimas e agressores em casa ${ }^{12}$.

Em relação ao número e à porcentagem de crimes letais contra mulheres segundo o mês e ano de ocorrência, pode-se observar que nos meses de abril, outubro, novembro e dezembro, há um número maior no total de vítimas e esse percentual se mantém maior e constante durante praticamente todos os anos da série. Em maio de 2020, mês de alta em número de casos de Covid-19 e com maior rigidez no isolamento social no Ceará (Decreto $n^{\circ} 33.608$ ), observa-se que houve um aumento no percentual de homicídios, reforçando as hipóteses levantadas no presente estudo de relação entre os dois fenômenos; nos meses seguintes, esse percentual diminuiu.

A necessidade de permanecer em suas residências também representa para algumas mulheres a continuidade em locais onde são perpetradas dinâmicas de poder, relacionamentos abusivos, violência física, psicológica e sexual. Mulheres em situação de violência tiveram vias de fuga diminuídas pelas 
restrições de locomoção durante período pandêmico de isolamento rígido, além de dificuldade de acesso a serviços de proteção às vítimas ${ }^{\mathbf{1 2}}$.

Nesse contexto da pandemia, as mulheres foram, em maiores ou menores níveis, obrigadas a permanecerem em suas casas com seus filhos e seus companheiros. A restrição de mobilidade, as dificuldades financeiras, o distanciamento dos demais membros familiares e o medo do contágio potencializaram e encorajaram os violentadores. Um fator que deve ser considerado é que o distanciamento social também acontecia nos serviços de proteção, o que levou a uma restrição nos atendimentos presenciais e, portanto, dificultou o acesso das vítimas a esses serviços ${ }^{13}$.

Outra observação apontada pelo presente estudo é a redução dos registros com a qualificadora feminicídio no ano de 2020 em relação ao ano anterior. De forma invertida, foram registrados mais homicídios dolosos em 2020 do que em 2019. Esse fenômeno nos leva a duas suposições: o número de feminicídio realmente diminuiu ou as mortes motivadas por questões de gênero não estão sendo registradas como deveriam. Além disso, o período pandêmico pode ter sido responsável por afetar o processo de trabalho durante as investigações do caso e sua caracterização devida como feminicídio.

No que se refere às faixas etárias mais acometidas, o 'Atlas da Violência 2020' corrobora os dados apresentados pelo presente estudo, ao indicar que no território brasileiro as mulheres jovens, com idades entre 15 e 29 anos, foram as principais vítimas de crimes letais entre os anos de 2008 e $2018^{11}$.

Os dados da SSPDS coletados não fornecem informações sobre os crimes letais e intencionais na perspectiva racial, mas esses números em outras fontes de pesquisa estão em ascensão. A ausência dessa variável na fonte do presente estudo dificulta a análise do fenômeno sob a perspectiva da interseccionalidade, uma vez que as questões de gênero não são os únicos problemas que atravessam a vida dessas mulheres e a experiência da violência contra mulheres brancas e negras é diferente devido ao racismo estrutural, recomendando-se a busca por outras fontes para melhor compreensão desses aspectos ${ }^{14}$.

O 'Atlas da Violência 2020' afirma que no Brasil, em 2018, do total de mulheres mortas, $68 \%$ eram negras e, entre os anos de 2008 e 2018 , houve um aumento de $12,4 \%$ nos homicídios de mulheres pretas; já o assassinato de mulheres não negras diminuiu $11,7 \%$ durante $o$ mesmo período. O Ceará ficou entre os quatro estados do Brasil em que o número de mulheres negras mortas é quatro vezes maior que o de mulheres não negras"1.

Em relação ao meio de agressão utilizado nos crimes contra as mulheres, o estudo observou que o principal é a arma de fogo, o que corrobora com a literatura que aponta a mesma circunstância para o Brasil. Entre os anos 2013 e 2018, o número de mulheres mortas por arma de fogo em suas residências aumentou em $25 \%$ no País"1. Em 2019, o governo federal emitiu o Projeto de Lei no ${ }^{\circ} .723 / 2019$ para ampliação e flexibilização de porte e posse de armas. Para especialistas, facilitar o acesso a armas de fogo pode agravar o número de feminicídios, considerando que este é o instrumento mais utilizado pelos agressores para o assassinato de suas vítimas. Além disso, para os pesquisadores, não existe evidência de que os projetos de leis criados para a pauta de armamento sejam baseados em estatísticas ${ }^{15}$.

Através da cultura patriarcal, a subordinação das mulheres e a violência sofrida por elas têm caráter estrutural por longas décadas. A partir dos papéis de gênero atribuídos a homens e mulheres pela sociedade, as relações de poder são desempenhadas baseadas em controle, dominação e opressão, resultando em discriminação e estereótipos que se refletem nas novas gerações nas esferas públicas, entendidas como: governo, politica, religião, escolas, mídia, dentre outros; e privadas, entendidas como família, parentes e pessoas próximas com algum vínculo afetivo. Esse cenário de controle, opressão e violências contra as mulheres tornou-se cada vez mais natural dentro 
das sociedades, gerando consequências gravíssimas à integridade física, psicológica e à vida das mulheres ${ }^{16}$.

As questões sobre a desigualdade de gênero vêm sendo debatidas desde o século passado internacionalmente. Desde a década de 1970, movimentos feministas começaram a pressionar com mais veemência a comunidade internacional, levando em consideração a realidade violenta enfrentada pelas mulheres. A partir desses movimentos, as mulheres vêm conquistando direitos emancipatórios, prioridade no contexto de proteção dos direitos humanos, reformas em legislações ${ }^{16}$.

De forma cronológica, podemos citar avanços importantes conquistados pelo movimento de mulheres no Brasil. A Constituição Federal de 1988, as conferências da Organização das Nações Unidas (ONU) e a Organização dos Estados Americanos (OEA) reafirmaram o preceito de dignidade humana na década de 1990. Ainda em 2001, o assédio sexual foi tipificado como crime. Em 2002, o Estado brasileiro apresentou relatório ao Comitê da Convenção para Eliminação de todas as Formas de Discriminação contra a Mulher (Cedaw) com amplo levantamento que deu visibilidade à violência contra a mulher. Nos anos que se seguiram, houve outros avanços nas políticas públicas de enfrentamento do problema frente aos esforços dos movimentos feministas, levando para os espaços de decisão e poder à necessidade de implementação de ações estratégicas e permanentes neste sentido ${ }^{17}$.

Apesar das conquistas importantes, o número de mulheres que sofrem violência, muitas delas letais, continua crescendo, e pelo simples fato de serem mulheres. Nos anos 1990, surgiu a primeira proposta de criminalização do feminicídio. Feministas estudiosas observaram que a violência de gênero ainda era naturalizada ou ignorada pelo direito penal. Na mesma década, muitos países da América Latina aprovaram reformas legais que tipificavam o homicídio de mulheres ${ }^{18}$.

Em 1976, a advogada Diana Russel utilizou pela primeira vez o termo 'femicídio' no Tribunal Internacional de Crimes contra
Mulheres em Bruxelas. O objetivo de Diana seria dar visibilidade às mortes de mulheres cometidas por homens. Para a advogada, o termo homicídio usado nesse tipo de crime neutralizava sua gravidade. Em 1990, Diana Russel redefiniu femicídio como ato final de um contínuo sistemático de terrores contra mulheres, fundamentado no patriarcado, que vai desde atos opressores físicos e psicológicos, procedimentos cirúrgicos forçados ou não, incesto, estupro de crianças e mulheres, procedimentos estéticos e outros atos violentos que resultem na morte de mulheres ${ }^{\mathbf{1 8}}$.

A partir do termo femicídio, originou-se a expressão feminicídio que, para Marcela Lagarde, representa a morte de mulheres cometida por homens em razão da condição de gênero, que acontecem dentro de um contexto de impunidade em que o Estado se mantém cúmplice quando não garante segurança à vida das mulheres; ou seja, o Estado tem responsabilidade na morte dessas mulheres ${ }^{\mathbf{1 8}}$.

O Brasil foi um dos últimos países da América Latina a tipificar o feminicídio. A Lei $n^{0} 13.104$ foi sancionada pela então presidenta Dilma Rousseff, no dia 9 de março de 2015. A Lei do Feminicídio qualifica o crime de homicídio de mulheres e o diferencia dos demais, reconhecendo que essa morte se deu por condições de desigualdade dentro do ambiente doméstico ou familiar e/ou em razão de menosprezo ou discriminação à condição de mulher ${ }^{19}$. As peculiaridades desse crime são o ódio e a aversão a mulheres, a crueldade e perversão explícita no corpo da vítima ${ }^{20}$.

Mesmo existindo uma lei, em vigor desde o ano de 2015, que dá conta dos crimes de feminicídio, ainda há muitos desafios a serem superados, tanto na implementação das políticas públicas, quanto no acesso à justiça. Diante do fato de um crime letal contra uma mulher, é necessário que a investigação, o processo e o julgamento estejam alinhados na perspectiva de gênero. Sem a percepção de gênero por parte dos operadores da justiça, os autores dos crimes não serão punidos como diz a lei e as vítimas não serão reparadas ${ }^{21}$. 
Há um Protocolo Latino-Americano para Investigação de Mortes Violentas de Mulheres a ser seguido pela polícia, Ministério Público, tribunais e defensorias; mesmo assim já foram identificadas irregularidades e omissões nas investigações e processos judiciais em casos de mortes por razão de gênero. É incabível e intolerável que vítimas de feminicídio sejam julgadas moralmente por suas condutas e histórias de vida e que tais julgamentos sejam considerados justificativas para culpá-las das agressões que sofreram ${ }^{21}$.

Nesse contexto, vale ressaltar que a figura feminina sofre pela forma como são socializados homens e mulheres numa sociedade racista, patriarcal e heteronormativa. Estabelecemse papéis de gênero que as colocam em um lugar de inferioridade em relação ao homem, de fragilidade e vulnerabilidade, seja pelas atividades desempenhadas, seja pelo exercício da maternidade 22 .

$\mathrm{Na}$ maioria das civilizações antigas, a mulher representava uma figura passiva, não possuindo participação na organização da família e sem autonomia em relação ao marido. Quanto a este, era responsável pelas decisões familiares, posse de escravos e outros papéis de poder, garantindo que a mulher permanecesse sob seu comando 22 .

Ao ser identificada como inferior, a mulher torna-se mais propensa a sofrer violência, muitas vezes causada pelas desiguais relações de gênero e apresentando-se de forma diversificada ao decorrer do tempo. Historicamente, a violência contra a mulher é algo que sempre fez parte da sociedade, sendo praticada principalmente por parceiros próximos e ocasionando sérios impactos na saúde e bem-estar social destas mulheres ${ }^{3}$.

A violência desferida contra as mulheres tem uma característica diferente das violências que os homens sofrem. Dificilmente as mulheres são vítimas de violência no trânsito, em brigas ou por dívidas; geralmente são pessoas próximas ou com vínculo afetivo, tais como companheiros ou ex-companheiros, avôs, pais, irmãos ou vizinhos que agridem ou matam mulheres. Além disso, as agressões geralmente acontecem em suas próprias casas, ou seja, o lugar de onde se espera segurança se tornou, para as mulheres, um ambiente hostil23.

Para entender as peculiaridades do fenômeno da violência, portanto, devemos considerar o conceito de gênero, uma vez que a Lei Maria da Penha (Lei $\left.n^{\circ} 11.340 / 2006\right)$ especifica, em seu art. $5^{\circ}$, que "configura violência doméstica contra a mulher qualquer ação ou omissão baseada no gênero" 24. Além disso, deve-se considerar os mecanismos do patriarcado de manutenção dos espaços hegemônicos de poder, dificultando o acesso de figuras que desempenhem papel de desconstrução e mudança dessa realidade, principalmente as mulheres negras ${ }^{13}$.

Para muitos estudiosos e pesquisadores, quando falamos de gênero, estamos falando da construção social de uma sociedade, ou seja, é a partir dessa construção que são determinados os papéis para homens e mulheres. Ainda no útero, os pais definem quais as cores do quarto, das roupas, dos brinquedos de seu bebê a partir do sexo biológico. Idealizam também como deverão se comportar e como irão educá-los baseados nos órgãos genitais dos filhos em uma perspectiva binarista, cisgênera e heteronormatica ${ }^{23}$. Nesse sentido, espera-se que os sujeitos apresentem um recorte de gênero universal e fixo que não inclui um conjunto de corpos e condições de vida dissidentes desta ordem social25.

Os meninos aprendem desde cedo a serem livres, exploram brincadeiras e brinquedos que denotam liberdade, poder e prestígio, além de serem incentivados a conquistar as profissões mais valorizadas pela sociedade. Já as meninas são consideradas seres delicados e que necessitam de mais cuidados. Portanto, para as meninas são oferecidos brinquedos que as treinem para o cuidado, para o lar e afazeres domésticos ${ }^{23}$.

Assim, a sociedade atribui diferenças biológicas às diferenças sociais e políticas, determinam hierarquicamente como homens 
e mulheres devem se comportar e se constituir. As mulheres aprendem que devem servir e lhes são impostos papéis de menor valor, logo, aos homens é conferido o poder sobre as mulheres; a esse poder damos o nome de patriarcado ${ }^{23}$.

Para Cunha ${ }^{\mathbf{2 6}}$, patriarcado caracteriza-se através de um regime de dominação e subordinação em que o homem ocupa o lugar central da família e representa a autoridade máxima, enquanto os demais membros da família devem obediência.

O patriarcado se mantém a partir de uma economia doméstica organizada, na qual as mulheres são consideradas apenas objetos de prazer e satisfação sexual, porém com sua importância na reprodução de herdeiros e na força de trabalho. É um sistema de dominação-exploração, que se mantém presente nas sociedades de hoje com novas configurações, apesar dos avanços conquistados ${ }^{25}$.

Através dessa estrutura sólida, desigual e disseminada culturalmente é que são mantidas, aceitas e validadas as relações de posse e violência dos homens sobre mulheres e são mais naturalizadas e potencializadas quando são associadas a outras vulnerabilidades como habitação, desemprego, racismo estrutural e baixa escolaridade, que vitimam de forma acentuada mulheres negras ${ }^{13,23}$.

Uma dificuldade encontrada durante a realização deste estudo, foi a limitação de dados disponíveis na plataforma em relação à vítima, tais quais raça, classe social, identidade de gênero e sobre a ocorrência do crime. Diante da percepção do crescimento da curva de crimes violentos letais e intencionais contra mulheres, torna-se essencial que as autoridades, as instituições, organizações sociais, comunidade acadêmica, profissionais de todos os setores e serviços públicos e privados estejam sensibilizados e empenhados em cobrar a efetivação das políticas de enfrentamento alinhadas a toda rede de serviços.

Podem-se apontar como limitações desta pesquisa questões inerentes à fonte de dados utilizada, que apresenta restrições relacionadas ao escopo de variáveis limitadas que não permitiram uma maior caracterização do perfil epidemiológico da amostra em questão. Além disso, o número de anos disponíveis ser reduzido pode ter impactado diretamente na não relevância estatística dos cálculos realizados na análise de tendência temporal.

Nesse contexto, vale ressaltar, ainda, que a violência de gênero é um fenômeno complexo e atravessado de subjetividades que podem não ser captadas em instrumentos quantitativos utilizados para a tabulação da fonte no momento da produção dos dados secundários. No entanto, o presente estudo buscou sanar essas questões subjetivas e mais profundas ao realizar um apanhado da literatura para articular com os resultados apresentados e complementar a compreensão do fenômeno.

\section{Considerações finais}

A violência contra a mulher no estado do Ceará encontra-se em ascensão e anos com eventos sanitários atípicos, como a pandemia da Covid19 , tendem a impactar negativamente a vida em sociedade e mais diretamente a vida das mulheres.

É urgente que a sociedade se empenhe em sanar todo mal que o patriarcado causa, especialmente às mulheres. Até o momento, as políticas de enfrentamento à violência contra a mulher têm contribuído no acareamento que a violência impõe, mas todos esses esforços ainda são insuficientes quando nos deparamos com o número tão elevado de mulheres mortas no estado e no Brasil.

Além disso, deve-se ressaltar a importância da coleta, análise e monitoramento de informações sobre o agravo perpetrado contra mulheres em sistemas oficiais, para que captem com qualidade e aproximação da realidade dados sobre feminicídio. O processo de vigilância deve ser feito também no setor saúde para auxílio na tomada de decisão de gestores e 
para o direcionamento de ações estratégicas e políticas de promoção do cuidado integral de mulheres em situação de violência.

Acredita-se que este trabalho poderá ser útil para nortear e sensibilizar autoridades para a pauta da violência no estado, além de fomentar outros estudos com a mesma temática.

\section{Referências}

1. Organização Mundial da Saúde. Relatório Mundial sobre Violência e Saúde. Genebra: OMS; 2002.

2. Silva LEL, Oliveira MLC. Violência contra a mulher: revisão sistemática da produção científica nacional no período de 2009 a 2013. Ciênc. Saúde Colet. 2015; 20(11):3523-32.

3. Organização Mundial da Saúde. Relatório Mundial sobre a Prevenção da Violência 2014. Genebra: OMS; 2014.

4. Waiselfisz JJ. Mapa da violência 2015: homicídio de mulheres no Brasil. Brasília, DF: Flacso Brasil; 2015. [acesso em 2021 dez 18]. Disponível em: chrome-extension://efaidnbmnnnibpcajpcglclefindmkaj/viewer.html?pdfurl=http\%3A\%2F\%2Fwww. onumulheres.org.br\%2Fwp-content $\% 2$ Fuploads $\%$ 2F2016\%2F04\%2FMapaViolencia_2015_mulheres. pdf $\&$ clen $=2038082 \&$ chunk $=$ true.

5. Osis MJMD. Paism: um marco na abordagem da saúde reprodutiva no Brasil. Cad. Saúde Pública. 1998; 14(supl1):25-32.

\section{Colaboradores}

Chagas ER (0000-0003-2228-5636)*, Oliveira FVA (0000-0001-6626-906X)* e Macena RHM (0000-0002-3320-8380)* contribuíram igualmente para a elaboração do manuscrito. and Contributor ID).
6. Brasil. Decreto ${ }^{\circ} 23769$, de 6 de agosto de 1985. Cria a Delegacia de Polícia de Defesa da Mulher. Diário Oficial do Estado de São Paulo. 7 Ago 1985.

7. Kind L, Orsini MLP, Nepomuceno V, et al. Subnotificação e (in)visibilidade da violência contra mulheres na atenção primária à saúde. Cad. Saúde Pública. 2013; 29(9):1805-15.

8. Organização das Nações Unidas. Declaração e plataforma de ação da IV Conferência Mundial Sobre a Mulher. Pequim: ONU; 1995.

9. Secretaria de Segurança Pública e Defesa Social. Estatísticas. 2020. [acesso em 2020 nov 2]. Disponível em: https://www.sspds.ce.gov.br/estatisticas-2/.

10. Instituto Brasileiro de Geografia e Estatísticas. Ceará. Cidades e estados. 2020. [acesso em 2021 fev 20]. Disponível em: https://www.ibge.gov.br/cidades-e-estados/ce.html.

11. Cerqueira D, Bueno S, coordenadores. Atlas da violência 2020. Brasília, DF: Ipea; 2020. 
12. Bradbury-Jones $\mathrm{C}$, Isham $\mathrm{L}$. The pandemic paradox: The consequences of COVID-19 on domestic violence. J. Clin. Nurs. 2020; 29(13-14):2047-9.

13. Marques R. Enfrentamento à violência doméstica e familiar contra mulher: feminicídio no Brasil. Fortaleza: Fundação Demócrito Rocha; 2020.

14. Butler J. Problemas de gênero: feminismo e subversão de identidade. Rio de Janeiro: Civilização Brasileira; 2003.

15. Agência Câmara de Notícias. Para especialistas, ampliação do porte de armas de fogo pode aumentar riscos para mulheres. 2019. [acesso em $2021 \mathrm{fev}$ 13]. Disponível em: https://www.camara.leg.br/ noticias/599507-para-especialistas-ampliacao-do-porte-de-armas-de-fogo-pode-aumentar-riscos-para-mulheres/.

16. Gebrim LM, Borges PCC. Violência de gênero: tipificar ou não o femicídio/feminicídio. Rev. inform. Legislat. 2014; 51(202):59-75.

17. Barsted LL. O progresso das mulheres no enfrentamento da violência. In: Barsted LL, Pitanguy J. O progresso das mulheres no Brasil 2003-2010. Rio de Janeiro: CEPIA; Brasília, DF: ONU Mulheres; 2011. p. 346-381.

18. Campos CH. Feminicídio no Brasil: uma análise crítico-feminista. Sist. Penal. Violência. 2015; 7(1):10315.

19. Brasil. Lei ${ }^{\circ} 13.104$, de 9 de março de 2015. Altera o art. 121 do Decreto-Lei 2.848, de 7 de dezembro de 1940 - Código Penal, para prever o feminicídio como circunstância qualificadora do crime de homicídio, e o art. $1^{\circ}$ da Lei 8.072, de 25 de julho de 1990, para incluir o feminicídio no rol dos crimes hediondos. Diário Oficial da União. 10 Mar 2015. [acesso em 2021 fev 9]. Disponível em: http://www.planalto.gov.br/ ccivil_03/_ato2015-2018/2015/lei/113104.htm.
20. Marques ES, Moraes CL, Hasselmann MH, et al. A violência contra mulheres, crianças e adolescentes em tempos de pandemia pela COVID-19: panorama, motivações e formas de enfrentamento. Cad. Saúde Pública. 2020; 36:e00074420.

21. Marley L. Enfrentamento à violência doméstica e familiar contra mulher: politicas e diretrizes nacionais para investigar, processar e julgar. Fortaleza: Fundação Demócrito Rocha; 2020.

22. Leite RM, Noronha RML. A violência contra a mulher: herança histórica e reflexo das influências culturais e religiosas. Rev. Direito. Dialogicidade. 2015; 6(1):3.

23. Carneiro I. Enfrentamento à violência doméstica e familiar contra mulher - o processo de debate e a construção de direitos. [curso]. Fortaleza: Fundação Demócrito Rocha; 2020.

24. Brasil. Lei n ${ }^{\circ} 11.340$, de 7 de agosto de 2006. Lei Maria da Penha. Diário Oficial da União. 8 Ago 2006. [acesso em 2021 fev 15]. Disponível em: http://www. planalto.gov.br/ccivil_03/Ato2004-2006/2006/Lei/ L11340.htm.

25. Saffioti HIB. Gênero, patriarcado, violência. São Paulo: Editora Fundação Perseu Abramo; 2004.

26. Cunha BM. Violência contra a mulher, direito e patriarcado: perspectivas de combate à violência de gênero. In: Anais da $16^{\circ}$ Jornada de Iniciação Científica de Direito da UFPR; 2014; 1-2 outubro 2014. Curitiba. Curitiba: UFPR; 2014. [acesso em 2020 nov 2]. Disponível em: http://www.petdireito.ufpr.br/index.php/ anais-da-xvi-jornada-de-iniciacao-cientifica-vol-1-n-5-curitiba-2014/.

Recebido em 15/04/2021

Aprovado em 24/10/2021

Conflito de interesses: inexistente

Suporte financeiro: não houve 